\title{
O Discurso da Qualidade da Educação e o Governo da Conduta Docente
}

\author{
Dulce Mari Silva Voss' \\ Maria Manuela Alves Garcia" \\ 'Universidade Federal do Pampa (UNIPAMPA), Bagé/RS - Brasil \\ "Universidade Federal de Pelotas (UFPEL), Pelotas/RS - Brasil
}

RESUMO - O Discurso da Qualidade da Educação e o Governo da Conduta Docente. O estudo analisa os efeitos de autorresponsabilização na conduta docente do discurso da qualidade da educação alicerçado na elevação do Índice de Desenvolvimento da Educação Básica (IDEB) com a política Compromisso Todos pela Educação, gestada através do Plano de Ações Articuladas (PAR), a partir de um conjunto de seis depoimentos de professoras que participaram da construção da política no contexto de um município do interior do Rio Grande do Sul, no período de 2008-2011. Utiliza os estudos de Michel Foucault sobre discurso e governamentalidade e, secundariamente, a noção de hegemonia a partir da obra de Ernesto Laclau para analisar os depoimentos. Conclui que o discurso da qualidade da educação via elevação do IDEB intensifica a vigilância sobre o trabalho das docentes.

Palavras-chave: Política Educacional. Qualidade da Educação. Índice de Desenvolvimento da Educação Básica (IDEB). Plano de Ações Articuladas (PAR). Autorresponsabilização Docente.

ABSTRACT - The Discourse of Quality in Education and the Government of Teacher's Behavior. This study analyzes the effects of self-accountability in teachers' behavior as of the discourse of quality in education based on the rise of the IDEB - Elementary Education Development Index - through the program "All for Education Commitment Plan", created by the PAR Joint Action Plan - from a set of interviews with 6 teachers who participated in the development of this policy at a local level in a municipality in Rio Grande do Sul between 2009 and 2011. Studies of Michel Foucault on discourse and governmentality and, secondarily, Laclau's notion of hegemony, have been used to analyze the interviews in the research. It was concluded that the discourse of quality of education by the IDEB rise contributes to an intensified supervision of teachers' work.

Keywords: Educational Policies. Quality in Education. Elementary Education Development Index (IDED). Joint Action Plan (PAR). Teachers' SelfAccountability.

Educação \& Realidade, Porto Alegre, v. 39, n. 2, p. 391-412, abr./jun. 2014.

Disponível em: <http://www.ufrgs.br/edu_realidade> 
O Discurso da Qualidade da Educação e o Governo da Conduta Docente

\section{Introdução}

Este artigo trata dos impactos gerados no governo da conduta docente pelas políticas nacionais de avaliação criadas pelo Estado brasileiro, as quais estão fundamentadas no discurso da qualidade da educação via elevação do Índice de Desenvolvimento da Educação Básica (IDEB) ${ }^{1}$. Nesse contexto, o Plano de Metas Compromisso Todos pela Educação (Brasil, Decreto Presidencial n. 6.094/2007) e o Plano de Ações Articuladas (PAR) constituem-se em mecanismos de operacionalização de ações a serem promovidas nas redes públicas de ensino voltadas à melhoria dos resultados nas avaliações nacionais.

$O$ estudo enfoca os efeitos de autorresponsabilização, gerados pelo discurso da qualidade da educação alicerçado na elevação do IDEB, a partir da análise da gestão do PAR num município do Rio Grande do Sul, que se constituiu no campo empírico de uma pesquisa de Doutoramento $^{2}$. Nessa pesquisa, foram analisados os discursos proferidos por um grupo de seis professoras que trabalhavam em cinco escolas da rede municipal (três urbanas e duas rurais), as quais participavam das avaliações nacionais. Essas professoras atuaram na gestão do PAR como membros da equipe que elaborou o plano e do Comitê Local responsável pelo acompanhamento e avaliação das ações planejadas. Os depoimentos das professoras foram coletados através de entrevistas semiestruturadas e tiveram como objetivo explorar as relações que os sujeitos tinham com as políticas e seus efeitos na gestão do PAR, na prática escolar e docente. Na análise dessas entrevistas, buscou-se problematizar o discurso das políticas educacionais investigadas como práticas que produziram, não apenas o que foi dito, mas os próprios sujeitos pedagógicos, especialmente docentes, à medida que o discurso tem efeitos de poder e saber que induzem à criação de certos regimes de verdade e à fabricação de subjetividades, agindo por meio de tecnologias de governo e autogoverno das condutas (Foucault, 1979; 2008a; 2008b).

Considera-se que o discurso da qualidade pela via do IDEB busca ajustar a educação às lógicas da produtividade e competitividade provenientes do padrão de qualidade empresarial, o que requer o controle dos resultados do ensino e a vigilância sobre o trabalho das escolas e dos professores para que as metas sejam atingidas. Essas práticas gerencialistas de controle do trabalho escolar e docente fabricam condutas docentes ancoradas na performatividade e na autorresponsabilização para o êxito dos resultados, conforme o discurso preconizado pelas políticas de avaliação nacional.

A exposição pública do IDEB atribuído às escolas e redes de ensino, além de servir para legitimar os regimes de verdade dos discursos oficiais que advogam a favor da transparência e do controle social sobre os resultados das avaliações nacionais, produz efeitos de vigilância sobre o trabalho das escolas e dos professores e acirram disputas entre as instituições e os sujeitos, fortalecendo as lógicas empresariais da concorrência e da competitividade na gestão da educação. 
Os baixos índices alcançados pelas escolas e redes de ensino públicas, expostos nos sites e documentos do Fundo Nacional de Desenvolvimento da Educação (FNDE) e do Ministério da Educação (MEC), funcionam como um mecanismo de interpelação da sociedade e dos órgãos administrativos nas esferas estaduais e municipais, para que assumam a responsabilidade em reverter a baixa produtividade do ensino, buscando elevar o IDEB.

Assim, o padrão de qualidade fundado no IDEB funciona como uma tecnologia ${ }^{3}$ de governo da educação, pois o desempenho escolar nas avaliações nacionais torna-se um mecanismo condicionador da gestão das escolas e do trabalho docente. Com isso, o IDEB cria formas de racionalização e operacionalização numérica de fatores multifacetados - reprovação, evasão escolar e desempenho nas avaliações oficiais - que enquadram a gestão das escolas e o trabalho dos/as professores/ as numa lógica gerencial e performativa.

Com isso, as tecnologias de governo do trabalho escolar e da conduta docente são movidas pela constante vigilância e pela regulação e intervenção permanente nas condições materiais, culturais, técnicas, educacionais, que não se restringem às ações e políticas do Estado, mas referem-se, também, à atuação da sociedade como um todo e de cada indivíduo em particular. As políticas de avaliação da educação e profissionalização docente visam administrar as condutas e as subjetividades humanas, estabelecendo suas regras e racionalizando suas maneiras de sentir e fazer. Implicam, portanto, no governo da conduta e da alma humana (Rose, 1998; 2002).

Defende-se neste artigo que o discurso da melhoria da qualidade da educação, centrado na elevação do IDEB, produz efeitos de autorresponsabilização no governo das condutas docentes, gerando sentimentos ambíguos e contraditórios que mesclam crítica e adesão, confiança e repúdio, culpa, vergonha e autodeterminação. O trabalho pedagógico é direcionado a uma política de resultados, na qual as circunstâncias econômicas, políticas, sociais e culturais que permeiam o exercício da profissão docente, o ensino e as escolas são ignoradas ou então subsumidas a problemas de desempenho e esforço pessoal e profissional. A qualidade na educação, neste sentido, perde o seu caráter de relação social e reduz-se a uma média estatística.

Tal argumentação é desenvolvida ao longo do texto, primeiramente buscando contextualizar as políticas nacionais de avaliação efetivadas pelo Estado brasileiro, a partir da década de 1980, e o debate fomentado em torno delas. Na mesma seção são apresentados os conceitos teóricos que serviram como categorias de análise (tecnologias de governo e autogoverno, gerencialismo, performatividade) dos discursos das professoras que participaram da pesquisa sobre o PAR, procurando evidenciar as implicações produzidas na conduta docente. Nos discursos das docentes acerca do que entendem por qualidade da educação na relação com o IDEB, evidenciou-se o caráter contraditório, ambíguo

Educação \& Realidade, Porto Alegre, v. 39, n. 2, p. 391-412, abr./jun. 2014. 393

Disponível em: <http://www.ufrgs.br/edu_realidade> 
O Discurso da Qualidade da Educação e o Governo da Conduta Docente

e híbrido de suas posições e a produção de efeitos de autorresponsabilização docente pelos fracassos e sucessos nos resultados das avaliações padronizadas. Por último, são feitas algumas considerações decorrentes do desenvolvimento da argumentação.

\section{Políticas Nacionais de Avaliação e suas Implicações na Formação e Profissionalização Docente}

A crescente implantação de programas e ações de avaliação da educação promovidas pelo Estado brasileiro tem provocado e intensificado o debate entre intelectuais e pesquisadores acerca dos pressupostos históricos, do caráter político e dos impactos gerados na formação e profissionalização docente pelas políticas educacionais em curso.

Retomando alguns estudos contemporâneos, é possível identificar posições políticas e linhas teóricas diferenciadas nas análises da problemática. Gatti (2009) apresenta um estudo detalhado das políticas de avaliação no Brasil, onde indica as décadas de 1960 e 1970 como o marco histórico dos processos de avaliação do rendimento escolar em nosso país, explicando que, naquele período, foram realizados testes e questionários com o objetivo de mensurar a aquisição de conhecimentos dos estudantes relacionada a outros elementos sociais, econômicos e culturais do universo estudantil, enquanto que a avaliação das políticas educacionais que enfocam o sistema nacional como um todo teve início entre os anos de 1978 e 1982.

Segundo Gatti (2009), ao longo das décadas de 1970 e 1980, as políticas de avaliação foram marcadas pela descontinuidade dos estudos e rupturas nas ações dos governos nacionais e regionais em razão das mudanças nos quadros das administrações públicas brasileira. A retomada dos estudos e debates sobre a avaliação da educação ocorreu ao final da década de 1980, quando o MEC assumiu o papel de avaliador do ensino promovido na Educação Básica. A autora relata que, nesse período, foram aplicados testes em dez capitais de estados brasileiros que levaram em conta as realidades locais, os quais foram usados num estudo piloto do rendimento escolar e se estenderam, posteriormente, a outras capitais e cidades do país.

Diz a autora que os indicadores levantados nesses estudos foram analisados por pesquisadores que constataram elevados índices de repetência e evasão escolar. Tais estudos serviram de subsídio para a implantação pelo MEC, em articulação com as Secretarias Estaduais de Educação, do Sistema Nacional de Avaliação da Educação Básica (SAEB), a partir de 1993, o qual reúne dados caracterizados pela autora em dois eixos: (1) acesso ao ensino básico e eficiência e (2) qualidade, entendida como: produto (desempenho dos estudantes); contexto (nível socioeconômico, perfil e condições de trabalho dos docentes e diretores, matriz organizacional da escola); processo (planejamento do ensino e da escola); insumos (infraestrutura, equipamentos, recursos 
didáticos). A autora considera ainda que os resultados médios obtidos através das avaliações do SAEB são preocupantes e indicam a precariedade das aprendizagens escolares.

Seguindo outra direção na análise do tema, Freitas (2012) define as atuais políticas de avaliação promovidas pelo Estado brasileiro como um avanço dos processos de privatização da educação, já experimentado sem êxito em outros países a partir de 1980, como os Estados Unidos e a Austrália. Segundo o autor, tais reformas refletem uma coalizão de forças formada por políticos, mídia, empresários, fundações e pesquisadores empenhados em melhorar a qualidade da educação pública, submetendo-a a uma lógica de responsabilização e meritocracia que se apoia numa racionalidade técnica gerencialista de avaliação do desempenho dos estudantes e das escolas via padronização de exames e testes para o monitoramento dos resultados do trabalho pedagógico, os quais servem de parâmetro para a distribuição de bônus e punições.

A padronização da mensuração do desempenho estudantil, das escolas e das redes de ensino público e privado no Brasil, também é analisada por Werle (2011) quando caracteriza a década de 1990 como o período em que governo federal promoveu a reestruturação das políticas de avaliação da educação em larga escala via centralização das decisões e ações no MEC, com a criação da Prova Brasil e do Exame Nacional do Ensino Médio (ENEM).

Conforme esclarece Werle (2011), as políticas nacionais de avaliação desenvolvidas pelo Estado brasileiro buscam respaldo no princípio de universalização do ensino obrigatório da Constituição Federal de 1988, mediante a operacionalização de ações desenvolvidas em regime de colaboração entre os entes federados que visam o alcance em todo o território nacional de um padrão mínimo de qualidade na educação. No mesmo sentido, a Lei de Diretrizes e Bases da Educação Nacional de 1996 reforça o discurso da regulação das políticas de avaliação pelas instâncias administrativas do Estado para melhoria da qualidade da educação.

Além disso, Werle (2011) afirma que, no final da década de 1990, frente aos acordos financeiros feitos com o Banco Mundial e às demandas das agências internacionais, o Brasil ingressou nas avaliações internacionais promovidas pela Organização das Nações Unidas para a Educação, Ciência e Cultura (UNESCO) e, no início dos anos 2000, passou a participar do Programa Internacional de Avaliação de Estudantes (Pisa) criado pela Organização de Cooperação e Desenvolvimento Econômico (OCDE).

Entre as medidas de operacionalização das políticas nacionais de avaliação implantadas pelo MEC, a partir de 2007, encontra-se o Plano de Desenvolvimento da Educação (PDE) que aponta, como uma de suas ações, a criação do Plano de Metas Compromisso Todos pela Educação e do Plano de Ações Articuladas (PAR) voltados ao estabelecimento de 
O Discurso da Qualidade da Educação e o Governo da Conduta Docente

acordos de cooperação técnica e financeira entre a União, os estados e municípios.

Com o PDE, o governo federal selou sua aliança com os empresários que, desde 2006, organizaram o movimento Todos pela Educação (TPE), exercendo forte influência nas políticas educacionais oficiais com a criação de uma agenda de metas $^{4}$ para a educação brasileira. Alguns membros do TPE assessoram atualmente a presidência da república brasileira e compõem os quadros administrativos das secretarias do MEC (Freitas, 2012).

Tais ações indicam que o Estado brasileiro vem aprimorando as políticas de avaliação aos moldes do projeto de gestão empresarial, mediante a intensificação do controle sobre o trabalho escolar e docente, visando certa eficácia nos resultados do ensino. Seguindo essa lógica de regulação, mensuração e controle, o discurso da qualidade da Educação via elevação do IDEB, que fundamenta o Plano de Metas Compromisso Todos pela Educação e o PAR, funciona como uma tecnologia de interpelação e responsabilização de gestores, professores/as e comunidades para o gerenciamento da Educação Básica em nome da qualidade. Busca-se criar uma situação de consenso capaz de articular os diferentes interesses dos sujeitos e grupos envolvidos na gestão das redes de ensino e das escolas, pois, à medida que as diferentes demandas, dispersas no jogo de disputas pela definição das políticas educacionais, são articuladas, o discurso da qualidade via IDEB assume um caráter hegemônico ${ }^{5}$.

As políticas de avaliação instituídas na Educação Básica através do IDEB também reforçam o discurso de competência profissional a ser medida pela avaliação de desempenhos dos/as professores/as para regulamentação das promoções por mérito nas carreiras docentes com base em critérios de produtividade, eficiência e eficácia. Com isso, as políticas educacionais brasileiras de avaliação da educação e de formação e profissionalização docente são influenciadas pelas exigências que o processo de globalização/mundialização tem produzido para a formação de um trabalhador mais flexível, eficiente e polivalente, portanto, adequado às demandas do mercado (Maués, 2003).

Nesse modelo de profissionalização, o professor é responsabilizado por sua formação permanente, como indica o texto das Diretrizes Curriculares Nacionais para a Formação de Professores da Educação Básica ao afirmar que:

[...] o desenvolvimento das competências profissionais é processual e a formação inicial é apenas a primeira etapa do desenvolvimento profissional permanente [...]. Caberá ainda ao professor, individualmente, identificar melhor suas necessidades de formação e empreender o esforço necessário para realizar sua parcela de investimento no próprio desenvolvimento profissional (Brasil, 2001, p. 10 e 63). 
Em 2010, nova estratégia de controle da carreira docente na Educação Básica foi criada com o Exame Nacional de Ingresso na Carreira Docente, justificado pela necessidade de aferir conhecimentos, habilidades e competências dos professores ingressantes para a avaliação da formação inicial e definição das políticas nacionais de formação continuada, o que, segundo Werle (2011), parece responder à demanda criada pela OCDE de institucionalização de um programa de avaliação dos professores que verifique as condições nas quais ocorre a docência e suas repercussões na qualidade do ensino.

As políticas de responsabilização repercutem diretamente na organização e gestão das redes públicas de ensino, no trabalho das escolas e no exercício da profissão docente. Conforme Oliveira (2004), a política de expansão do acesso à escolarização, ancorada no discurso da educação como fator de equidade social, foi assumida como compromisso pelos países em desenvolvimento na Conferência Mundial sobre Educação para Todos (Jomtien, 1990), os quais criaram estratégias para aumentar o atendimento às populações sem, no entanto, ampliar na mesma proporção os investimentos. Desse modo, destaca a autora que, nas políticas educacionais da América Latina, a equidade de acesso à educação é marcada pela padronização e massificação de processos administrativos e pedagógicos que permitam baixar custos ou redefinir gastos, mediante a complementação orçamentária de recursos da própria comunidade ou de parcerias, combinados com o controle central na formulação das políticas.

Frente à necessidade de expansão do acesso e o modelo de gestão pautado na responsabilização e no controle técnico dos resultados do ensino, cabe ao professor responder para além de sua formação inicial, desempenhando inúmeras funções, o que contribui para um sentimento de desprofissionalização, de desqualificação do profissional docente. Desse modo, as reformas nas políticas de formação e profissionalização trazem à tona, novamente, a necessidade do debate sobre a precarização do trabalho docente num contexto de ampliação das exigências no exercício da profissão - domínio de novas tecnologias, pedagogia das competências, transversalidade dos saberes, avaliações formativas, participação na gestão escolar, promoções por mérito, premiações e penalizações, entre outras formas de flexibilização curricular associadas ao controle do desempenho profissional que passam a governar a docência e a conduta dos professores.

As políticas de responsabilização indicam que um novo método de governo está tomando forma: o governo das escolhas regulamentadas dos cidadãos individuais, construídos discursivamente como sujeitos de aspirações, liberdades, sujeitos autogovernados, capazes de conectar suas práticas com procedimentos e instrumentos que lhes deem determinados efeitos. As políticas de responsabilização procuram governar os indivíduos, agenciar suas subjetividades, de modo a fabricar sujeitos de determinado tipo. Na vida política, assim como no trabalho 
O Discurso da Qualidade da Educação e o Governo da Conduta Docente

ou no espaço doméstico, os seres humanos são interpelados a produzirem sua subjetividade motivada por aspirações à autorrealização. Essas práticas de subjetivação são historicamente contingentes, e interpelam os indivíduos a compreender a si mesmos, colocar a si mesmos em ação e julgar a si mesmos (Rose, 2002).

Peters, Marshall e Fitzsimons (2004) chamam essa nova forma de poder de busnopower, a qual é dirigida à subjetividade da pessoa através, não do corpo, mas da mente, para que as pessoas aceitem certas verdades a respeito de si mesmas. O busnopower não é dirigido apenas às pessoas individualmente, para transformá-las em sujeitos escolhedores autônomos e consumidores, mas à população como um todo pela imersão do social na cultura empresarial. Assim, a resolução de problemas pelas próprias escolas envolve, essencialmente, a despolitização da educação enquanto direito social, em nome da qualidade empresarial negociada entre os estudantes, os pais e o provedor.

Os autores escrevem sobre o gerencialismo como uma expressão ou tecnologia do neoliberalismo, cujas teorias e modelos foram usados para eliminar as práticas burocráticas das instituições e políticas públicas, em nome de legitimar a descentralização da gestão e estabelecer meios instrumentais de controle local dos contratos entre setores públicos e privados e de novas estruturas de responsabilização e financiamento, condicionadas a resultados quantificáveis e desempenhos. Assim, o gerencialismo torna-se uma forma de autogoverno que traz consigo uma noção de um escolhedor autônomo, mas que não será um indivíduo livre, pois as formas de racionalidade e as leis pelas quais o mercado opera irão moldar as pessoas como tipos específicos de sujeitos para que escolham a partir de uma perspectiva geral. Os sujeitos são governados e autogovernados porque acreditam que escolhem de forma autônoma (Peters; Marshall; Fitzsimons, 2004).

As políticas gerencialistas adotadas pelo Estado brasileiro no caso da educação pautam-se fundamentalmente pela lógica do quase mercado (Whitty, 1997), diferindo do caso de alguns países como os Estados Unidos ou a Inglaterra, em que há privatizações de instituições públicas no sentido restrito e/ou o estabelecimento de parcerias público-privado na gestão de instituições que, até então, eram mantidas e administradas pelo Estado. O conceito de quase mercado não implica a transferência da instituição pública para o setor privado, mas sim a sua mercantilização e submissão a valores de ordem empresarial, características, sem dúvida, hoje presentes nas políticas educacionais e de avaliação de sistema no Brasil: manutenção do Estado gestor e provedor das políticas educacionais, mesmo com o crescimento, por exemplo, dos sistemas de apostilamento e de responsabilização da sociedade civil com a sustentação, o desempenho e a auditoria das instituições; ênfase nos resultados e desempenhos finais; preocupação em instituir controles mais distantes e centrados na auditoria desses resultados, comprometendo os indivíduos com suas próprias performances; estímulo a uma ética 
concorrencial; e disseminação de uma nova racionalidade e linguagem acerca da qualidade na educação.

O gerencialismo e a performatividade estão presentes nos discursos oficiais das políticas de avaliação que reordenam a gestão da Educação Básica, os quais atribuem aos sujeitos a responsabilidade por elevar a qualidade da educação por meio da intervenção nos desempenhos e nos resultados do ensino. A performatividade é resultado da funcionalidade, instrumentalidade e mercantilização do saber exteriorizado, medido e classificado. A constante recolha e publicação de dados relativos aos desempenhos escolares e do alunado constituem práticas utilitaristas que favorecem as relações de mercado. Essas práticas também afetam o profissionalismo docente, pois os professores são convocados a maximizar os desempenhos dos alunos. Fazer um bom trabalho, demonstrar competência profissional passa a significar para o professor garantir a excelência dos resultados, podendo, inclusive, receber recompensas em seus salários. Dessa forma, o trabalho docente também adquire valor de mercado (Ball, 2005).

Os professores acabam inseridos na performatividade pelo empenho com que tentam corresponder aos novos e inconciliáveis imperativos da competição e do cumprimento de metas. O profissional docente é encorajado a refletir sobre si próprio como indivíduo que faz cálculos, que age movido pelos indicadores e índices que representam sua produtividade profissional (Ball, 2002).

Atuando de fora para dentro e de dentro para fora, as práticas performativas objetivam a construção cultural da crença na qualidade dos serviços e do orgulho pessoal e institucional pelo produto alcançado. Mas, as constantes avaliações e classificações, presentes nas práticas gerenciais e performativas dos sujeitos, grupos e instituições, como argumenta Ball (2010, p. 40), “[...] podem engendrar sentimentos individuais de orgulho, de culpa, de vergonha e de inveja”.

As políticas de avaliação pautadas em tecnologias gerencialistas e performativas fabricam formas de controle do trabalho escolar e docente, na medida em que servem como medidas de produtividade das ações dos sujeitos pedagógicos frente ao desafio de alcançar a qualidade da educação traduzida na maximização dos resultados do ensino. Nela, o julgamento, a prestação de contas e a competição são cruciais para a qualidade dos serviços educacionais. Sendo assim, há uma luta por visibilidade, fundada no discurso da transparência e em tecnologias performativas de regulação social, visando à reforma dos sentidos e das identidades profissionais. Um fluxo de demandas, expectativas e indicadores que tornam os sujeitos continuamente responsáveis e autorresponsáveis pelos fracassos ou êxitos alcançados.

Educação \& Realidade, Porto Alegre, v. 39, n. 2, p. 391-412, abr./jun. 2014.

Disponível em: <http://www.ufrgs.br/edu_realidade> 
O Discurso da Qualidade da Educação e o Governo da Conduta Docente

\section{A Qualidade da Educação Via o IDEB e o Governo da Conduta Docente}

O Plano de Metas Compromisso Todos pela Educação aponta para a necessidade de uma aliança entre os governos federal, estadual e municipal, os profissionais da educação, entidades e outros setores sociais em prol de melhores resultados no ensino em termos de índices de avaliação. Uma política de resultados que requer a mobilização coletiva.

A pesquisa da gestão do PAR numa rede municipal de ensino do Rio Grande do Sul, de 2008 a 2011, possibilitou a análise dos efeitos gerados pelas políticas oficiais, pautadas no controle dos resultados e na regulação da gestão escolar e do trabalho dos/as professores/as, o que implica no autogoverno da conduta docente.

No contexto pesquisado, a política Compromisso Todos pela Educação foi justificada e celebrada pela possibilidade de apoio técnico e financeiro prestado pelo MEC aos entes federados. As professoras entrevistadas reconheceram nessa iniciativa, mesmo que de modo um tanto difuso, o empenho, tanto da esfera municipal como federal, para a melhoria da qualidade da educação. Os sujeitos locais aderiram ao Plano Compromisso Todos pela Educação, elaborando o PAR e procurando efetivar suas ações. Assim, demonstraram compreender que, ao cumprir seu papel de elevar os índices, estavam colaborando para a melhoria da educação, no seu município e, consequentemente, no cenário nacional:

Se a gente para para analisar, há algum tempo atrás não se podia imaginar que nós educadores pudesse estar... de alguma forma, que lá num pontinho do RS, pudesse estar alimentando um sistema que vai ajudar ao MEC, como a entidade máxima de Educação em nosso país, a começar a pontuar, a começar a delinear ações estratégicas para dar conta dessas demandas que a comunidade indica. Então, eu acho, eu tenho plena convicção de que isso é um instrumento bastante valioso pra conseguir auxiliar na gestão de políticas no sentido assim mais macro (professora Luiza).

As professoras entrevistadas consideraram que a exposição pública do IDEB $^{6}$ deu visibilidade ao município e às escolas e, embora aumentasse internamente a competição e as disputas por recursos financeiros e pedagógicos, reafirmaram a importância de conhecer e divulgar os índices, para alertar a comunidade e comprometer os profissionais da educação com a melhoria dos desempenhos:

Então, o que eu sei desse plano é daquele trabalho que eu participei do PAR, das ações aquelas que foram lançadas, não sei bem o termo... Do trabalho do município, porque estava entre os municípios prioritários e aí foi nos colocado, que é um trabalho do todo, como já diz, não só os envolvidos mais diretamente com a educação, mas toda a sociedade voltada à melhoria da educação. Dentro disso, desse projeto foram lançadas as ações que a gente tem que trabalhar aqui no município, tem que procurar desenvolver as ações para que melhore a educação no município e no todo (professora Laura). 
As falas das professoras entrevistadas permitem afirmar que estas atribuíram legitimidade ao discurso oficial da melhoria da qualidade da educação pela elevação do IDEB, reafirmando as fragilidades no ensino local apontadas pelo MEC e a necessidade de adotar as estratégias de superação através da implantação das ações do PAR:

Realmente, nosso município estava numa defasagem muito grande, era um dos municípios com menos rendimento, no caso, pelas análises do IDEB. Eu acredito que tenha sido por isso também. Que eles estão, nesse momento, em prol de que as coisas têm que melhorar (professora Ester).

Quando a gente ouve, em reuniões, que nosso município é um dos piores municípios, isso dói, isso dói muito, sabe? Por que não podemos só culpar o governo, não, somos todos nós, então a gente sente muito. $\mathrm{O}$ nosso município já foi muito bem na educação, ele era assim... E agora tá mal (professora Márcia).

Significante e significado construíram-se mutuamente no discurso, pois, melhorar a qualidade da educação passou a significar, necessariamente, aumentar o aproveitamento e o rendimento escolar. No entanto, afirmaram sua adesão à política Compromisso Todos pela Educação, motivadas por outros interesses além da preocupação com o IDEB. Houve aquelas que disseram esperar por condições mais dignas de trabalho, maiores oportunidades de formação e melhor remuneração:

A minha expectativa, eu acho que cada vez mais tem que se darem condições para que se possa fazer um bom trabalho e não só condições materiais mas também atualização, aperfeiçoamento, toda essa parte que a gente vê ainda não como a gente gostaria, mas que está começando (professora Carla).

O Compromisso Todos pela Educação, o que é? A melhoria de qualidade da nossa educação em várias áreas, tanto pedagógicas, quanto administrativas e mesmo do salário do professor, o... O Piso Nacional e outras ações. Mas, se nós olharmos, ainda falta muito, muito (professora Márcia).

Ao definirem a qualidade da educação, as entrevistadas produziram múltiplos e híbridos sentidos que mesclaram autonomia, aprendizagem, melhores condições de trabalho docente (em termos de infraestrutura e recursos didático-pedagógicos), formação docente, espaços de reflexão e discussão coletiva e, simultaneamente, a necessidade de atenção dos/as professores/as aos índices atribuídos à educação, às taxas de reprovação e evasão escolar. Como foi proferido nos discursos:

Qualidade ela passa, eu entendo, por todas essas questões que a gente já mencionou. As condições físicas do prédio, de mobiliários adequados, e todas as condições que garantam que o aluno consiga chegar até a escola e ter o espaço agradável, aprazível, um ambiente que favoreça os diversos sujeitos que estejam envolvidos nessa ação, que estejam convictos de sua atuação. O servidor, o funcionário tem que saber qual é a sua função e como isso tem resultado no processo de aprendizagem. A qualificação dos professores, a oportunidade da escola criar espaços de discussão e de 
formação permanente dos seus professores. Entendo que a qualidade da educação passa sim por essas questões todas, passa também pela discussão com as entidades do Ensino Superior na formatação de seus cursos. Então, tem uma série de demandas, digamos assim, que temos que discutir e refletir em conjunto com vários entes: que qualidade nós queremos, que limites nós temos e como a gente se propõe a fazer os avanços dentro daquilo que a gente se propõe a fazer (professora Luiza).

Eu entendo a qualidade como uma maneira de que todos os que estão na escola, aprendam. A qualidade da educação seria assim, como descobrir esses meios, se sabe que é bem amplo e nós todos estamos tentando, uma forma para que todos consigam aprender e adquirir essa aprendizagem para sua vida, porque o que a gente aprende hoje, a gente leva para o resto da vida (professora Ester).

Penso que a qualidade é toda aquela infraestrutura necessária para trabalhar, principalmente na questão pedagógica, que eu acho que é a preocupação primeira que as escolas têm que ter, a parte pedagógica da escola, formação para os professores, formação continuada, assim, dar a estrutura necessária que o professor possa trabalhar. É... Ficar atenta a esses índices de evasão e repetência, não se preocupar com a prova externa, mas assim, qualificar o trabalho do professor na escola, fazer os atendimentos individuais necessários, buscar, de uma maneira ou de outra, aquele aluno que tenha dificuldade, a gente ver uma maneira... Então, qualidade na educação pra mim é isso, é realmente índice de aprovação em que haja garantia de aprendizagem, isso é qualidade da educação (professora Márcia).

A busca por melhores resultados, que indicariam maior qualidade do ensino, foi também justificada pela necessidade de preparar os/as alunos/as para competir pelas vagas em instituições federais de ensino médio e superior:

Pra mim a qualidade da educação seria a gente conseguir que os nossos alunos saiam com um nível bom, em condições de fazer o vestibular. Muitos fazem o vestibular no IF-Sul no CAVG e se saem bem. Nós temos assim a totalidade dos nossos alunos que querem, se não passam num primeiro momento, mas já estão conseguindo, estão competindo em condições praticamente iguais com aqueles das escolas maiores (professora Carla).

A qualidade da educação dependeria, também, do chamado comprometimento do professor e do amor no exercício da profissão docente, como referido nas falas:

Qualidade da educação, para mim, somos todos nós educadores comprometidos para que essa educação seja... Para que seja aprendizagem. Qualidade, para mim, é aprendizagem, é o meu aluno saber, ter condições de se posicionar, de interpretar e ser entendido (professora Laura).

Eu penso que ter qualidade é trabalhar com amor, é enxergar em cada criança, dentro da sua sala de aula, a diferença de cada um e trabalhar ali para o mesmo objetivo, a aprendizagem. Qualidade é aprendizagem, é avanço conforme aquela pessoa, seja lá da Educação Infantil, da EJA, que essa criança todos os dias saia feliz daquela escola, com um pouquinho de conhecimento (professora Rute). 
Nos discursos híbridos destas professoras, foram associados diversos significantes (amor, competência técnica, condições de trabalho, salários, formação e comprometimento do professor, aprendizagem, resultados e preparação do aluno para a aprovação em concursos) ao conceito de qualidade via IDEB, formando uma totalidade discursiva contraditória e ambivalente. Na busca de produzirem um sentido verdadeiro, as professoras lançaram mão de diversos fragmentos discursivos trazidos de suas trajetórias de formação profissional, de suas experiências de docência e dos discursos das políticas educacionais oficiais, que circulam em diversos veículos e espaços sociais e vêm responsabilizando os professores pelo sucesso nos resultados das avaliações nacionais. Nos discursos das entrevistadas também aparecem traços marcantes dos discursos das pedagogias críticas, na medida em que se referiram a uma postura virtuosa do/a professor/a e à ideia de um sujeito cuja moral e dedicação serviriam para intensificar o interesse do aluno e melhorar a qualidade do ensino.

Mesmo frente à desvalorização social que o magistério da Educação Básica vem sofrendo, desde os anos da década de 1960 no Brasil, ainda é parte do nosso imaginário social e regime ético pensar na docência como uma personalidade prestigiosa e uma função carismática, na qual o professor se destaca por atributos como a vocação, a paixão e o compromisso moral, como guardião de valores universais como justiça, humanização e verdade. Se as condições materiais da profissão docente se assemelham às de um funcionário civil, cujo trabalho vem sendo crescentemente proletarizado, a formação desse profissional é, ainda em grande parte, decididamente pastoral, vocacional, pois a docência é encarada como uma missão que exige paixão e compromisso moral de seus praticantes (Garcia, 2009).

Os discursos das professoras entrevistadas levam a crer que, a qualidade da educação como elevação do IDEB foi legitimada pelos sujeitos, alinhando a preocupação com a evolução dos índices a outras demandas, como reconhecimento da necessidade de melhorar a aprendizagem, de investir nas condições de trabalho, na remuneração dos professores e na valorização profissional. Criou-se, assim, a ideia de qualidade via IDEB como um regime de verdade capaz de articular as demandas dos diferentes sujeitos que passaram a agir em torno desse discurso hegemônico. Em nome desse acordo, e criando expectativas, as professoras jogaram-se na luta para melhorar os desempenhos das escolas e dos/as alunos/as, acreditando estarem cumprindo seu papel enquanto profissionais competentes e comprometidas com a qualidade da educação.

O discurso do IDEB como indicador da qualidade do ensino e o reconhecimento da iniciativa da política educacional oficial está presente nas falas das professoras que se seguem:

Educação \& Realidade, Porto Alegre, v. 39, n. 2, p. 391-412, abr./jun. 2014.

Disponível em: <http://www.ufrgs.br/edu_realidade> 
Eu vejo pelo baixo índice o caos na Educação e o governo precisava fazer alguma coisa, porque realmente a educação tá bem complicada (professora Rute).

O objetivo final foi pra educação no Brasil, o IDEB. Eu acredito que todas essas iniciativas foram pra levar a uma melhor qualidade da educação, melhores resultados, melhores índices (professora Carla).

Os problemas apresentados na educação, a defasagem com a questão da aprendizagem dos nossos alunos... O baixo grau de escolaridade da população, o índice mesmo, o baixo índice que foi constatado, que a criança frequenta a escola há vários anos e não está preparada para aquela série que ela está (professora Laura).

Ao mesmo tempo, algumas professoras entrevistadas consideraram o IDEB uma política de risco, pois avaliaram que a elevação nos índices poderia ocorrer sem a devida qualidade da educação:

Acho uma política de risco basear-se só no IDEB, porque, como eu já disse, para mim a qualidade não se comprova só com resultados, não só aprovado ou reprovado. Quando se diz: temos que melhorar o IDEB, se corre o risco de aprovar sem qualidade. Eu brigo muito nas escolas que eu trabalho porque eu digo que não importa só IDEB, o que importa é melhorar com qualidade. Eu desconfio que o aumento do índice de aprovação seja o medo de reprovar. Os professores se sentem de certa forma forçados a aprovar. É exatamente isso que eu sinto e é exatamente isso que a gente escuta dentro das escolas (professora Carla).

Eu acho que ele auxilia na qualidade, mas eu acho que a gente tem que ter um cuidado também de não só levar em conta os números e de ver realmente se a coisa está andando, está fluindo, se os alunos estão aprendendo. Mas eu acho que é muito válido. Tem que ter esse IDEB. Ele é um indicador, mas tem que ter muito cuidado porque têm outras questões que estão envolvidas e cada escola vai ter a sua realidade (professora Ester).

Os discursos das professoras entrevistadas apresentam ambiguidades em relação ao IDEB, pois, ao mesmo tempo, afirmam a relevância desse indicador, como elemento de avaliação da qualidade do ensino, e advertem sobre os riscos de uma política centrada na elevação e na exposição pública dos resultados, ao levantarem a suspeita de que alguns professores, por medo ou para evitarem constrangimentos, podem não reprovar os alunos. As professoras se posicionaram contra a aprovação compulsória dos alunos e expressaram a necessidade de terem autonomia e competência para avaliá-los:

Porque, o que a gente tem claro há alguns anos trabalhando, é assim, que não é para aprovar o aluno só pelo fato de aprovar, só para ter lá um índice bom de aproveitamento, que esse aluno tem que ter o mínimo. Porque nós consideramos que a situação do município é uma educação de boa qualidade, a gente exige do nosso aluno, a gente se compromete com a educação e na hora da avaliação, reflete (professora Laura).

Eu digo pras gurias: eu não tenho preocupação nenhuma com o IDEB, meu compromisso é melhorar o índice de aproveitamento com qualidade, o aluno tem que sair preparado (professora Carla). 
As professoras relataram sobre as constantes práticas de controle nas avaliações dos/as alunos/as e das escolas e da pressão que sofriam em razão de terem que mostrar resultados:

O diretor quer que essa escola não tenha um índice tão baixo assim. Existe até certas pessoas que fazem certa pressão para que o índice seja melhor e esse é o grande risco de avaliar a qualidade da Educação pelo IDEB. Não é só o índice que vai nos dizer se há qualidade. Acho que a comparação dos desempenhos das escolas vai contribuir mais para a aprovação sem qualidade (professora Carla).

O controle e a pressão sobre o trabalho docente, em nome de uma qualidade que é traduzida numa média estatística, pareceu ser uma prática sofrida e arriscada, pois priorizou a aprovação a despeito das condições e circunstâncias em que as avaliações eram produzidas. A autorresponsabilização foi um dos efeitos destacados pelas professoras em virtude do controle e da cobrança constante por resultados, fazendo com que, no governo e autogoverno das práticas docentes, cobrassem de si e dos outros melhores desempenhos, conforme indicam os relatos:

Existe uma pressão da equipe diretiva em cima dos professores para melhorar os índices de aproveitamento, de aprovação. E, tudo isso atinge, é claro que atinge o professor, cada vez mais o professor é desvalorizado, porque se tu tens que passar, tem que passar... E isso aí é complicado (professora Carla).

Então, quando tu já consegues que o professor tenha um compromisso com aquele seu aluno, que ele busca fazer aquela avaliação também para detectar os possíveis erros, para trabalhar em cima daquilo ali, para que o aluno melhore. Nenhum professor quer, eu acredito, o fracasso, a escola tem que trabalhar para o sucesso, porque o fracasso do meu aluno é o meu fracasso (professora Márcia).

Eu vejo que nós precisamos, mesmo doendo, a gente precisa enxergar a realidade, pensar que está tudo muito bem, muito bem e continuar errando... Como educador, nós precisamos fazer a nossa parte. Eu vejo, me vejo como educadora, culpada pelo fracasso escolar. A gente pode melhorar. A culpa não é do governo, a culpa não é da pobreza, não é do aluno que não aprende. Eu sei que o professor deveria ser mais valorizado, que deveria ganhar um salário bom, mas somos nós que precisamos mudar. Aquele que vai lá com amor, ele vai chegar motivado e aquela turma vai embora (professora Rute).

Ao se referirem à vigilância e à regulação do trabalho docente, as professoras mesclaram sentimentos de culpa e vergonha com as ideias de estímulo e necessária motivação para que, em sua atuação profissional, se mobilizassem por melhores desempenhos. Ao se autorresponsabilizarem pelo sucesso (ou pelo fracasso) da aprendizagem de seus alunos, as professoras posicionaram-se como sujeitos que falam não apenas da experiência vivida, mas de si mesmas no interior dessas práticas. Seus discursos estavam, assim, amarrados a uma descrição de si como pessoa e professora que deveriam ser, ou vir a ser, para terem êxito e alcançarem o sucesso em sua tarefa:

Educação \& Realidade, Porto Alegre, v. 39, n. 2, p. 391-412, abr./jun. 2014 405

Disponível em: <http://www.ufrgs.br/edu_realidade> 
Eu sentia que, como professora, eu tinha que me empenhar para que aquele resultado aparecesse. Por um comprometimento meu. Eu não posso dizer se as colegas sentiam a mesma coisa. Parece que a gente [se] cobra mais, que a gente tem que mostrar serviço, digamos assim (professora Ester).

Eu sempre me questiono muito: será que eu estou fazendo certo? E eu tento fazer o melhor para motivar meus alunos. Isso aí faz a gente pensar, se há uma cobrança tu tentas fazer melhor. Agora está tendo o Índice, isso aí serve para provocar o professor. E tu sente também um pouco... Como vou dizer... vigiada, por um lado é ruim, ser cobrado. Eu não sei, posso estar falando contra mim mesmo... (professora Sandra).

No início do segundo semestre ela vai fazer uma reunião, por isso que ela pede, que cada final de bimestre a gente mande para... Lá como é que está indo. Depois ela faz uma reunião por escola, para as diretoras e no final do ano também, como é que foi esse trabalho. Esse momento é o momento que a gente fica assim, com vontade de entrar para baixo da mesa (risos). Porque... A gente vai analisando e é uma das coisas que eu peço para a minha equipe, para as coordenadoras: eu vou cobrar de vocês! (professora Rute).

Ao falarem de sua participação nas políticas de avaliação em suas escolas e rede de ensino, as professoras utilizam o que Larrosa (1994) denomina de tecnologias óticas de autorreflexão, ou seja, desenvolvem um modo de falar, no qual tomam a si próprias e suas condutas como matéria de reflexão e autorreflexão, em relação a objetivos e a uma moralidade com a qual parecem já identificadas, mas que, na verdade, foi ou ainda é, em alguns momentos, uma demanda exterior, absurda e eminentemente administrativa.

Os sentimentos de culpa, de vergonha e de cobrança, presentes nos discursos das professoras, foram produzidos na relação delas consigo mesmas como formas discursivas de autoexpressão, autoavaliação, autocontrole e autotransformação. Essas práticas configuraram-se, no interior dos discursos docentes, como tecnologias de saber, poder e subjetivação, pois o que se pretende transformar não é apenas o que cada professora faz ou sabe sobre a política, mas sua própria maneira de ser e fazer-se. Ao serem inquiridas na situação de entrevista, sobre o que pensavam sobre o IDEB enquanto um indicador da qualidade da Educação Básica e o modo como se relacionavam com essa política no cotidiano do seu trabalho:

É como se o sujeito da reflexão, além de possuir a capacidade de ver-se, tivesse também um critério ou padrão que lhe permitisse avaliar o que vê, criticar-se. E esse critério, seja ele imposto ou construído, absoluto ou relativo, é o que lhe permite estabelecer o verdadeiro e o falso do eu, o bom e o mau, o belo e o feio. Assim, sob um olhar criterial que transporta todo um conjunto de oposições, o visível pode ficar avaliado, distinguido por seu valor, marcado positiva ou negativamente. Por outro lado, o expressar-se, quando cai sob a lógica da autocrítica, não é senão exteriorizar o que foi avaliado, tornar pública uma atri- 
buição de valor que teve previamente lugar na intimidade da consciência. E a atribuição de valor assim expressada expõe tanto o que foi marcado positiva ou negativamente quanto o critério de valoração utilizado. Por fim, o narrar-se como autocrítica adota decididamente essa função de 'prestar conta' de si mesmo segundo a lógica dos critérios de valor que servem de padrão da contabilidade (Larrosa, 1994, p. 74).

De acordo com Rose (1998), a administração do eu contemporâneo acontece através de certos mecanismos, como a incorporação das capacidades pessoais e subjetivas dos cidadãos aos poderes públicos, por meio de estratégias sociais e políticas e de instituiçõos e técnicas de administração e regulação da conduta. Em suas palavras:

A subjetividade faz parte dos cálculos das forças políticas no que diz respeito ao estado da nação, às possibilidades e aos problemas enfrentados pelo país, às prioridades e às políticas. Os governos e os partidos têm formulado políticas, movimentando toda uma maquinaria, estabelecido burocracias e promovido iniciativas para regular a conduta dos cidadãos através de uma ação sobre suas capacidades e propensões mentais (Rose, 1998, p. 31).

Sendo assim, a alma do cidadão entra de forma direta no discurso político e na prática de governo, pois a administração da subjetividade tem se tornado uma tarefa central das organizações modernas que buscam preencher os espaços entre a vida privada e a vida pública. $\mathrm{O}$ governo da alma acontece com o surgimento de expertises da subjetividade, grupos de profissionais (psicólogos, orientadores, terapeutas, gerenciadores de pessoas entre outros) que reivindicam autoridade e legitimidade social em nome da capacidade de compreender aspectos psicológicos das pessoas e de agirem sobre eles ou de aconselhá-las no como agir. Essas formas de administrar a subjetividade afetam nossas crenças, desejos e aspirações, nossa ética. Nossas formas de falar e pensar sobre nossos sentimentos e ações têm sido (re)moldadas no sentido de conduzir nossas trocas com o mundo, com os outros e nós mesmos (Rose, 1998).

Portanto, a produção da subjetividade não é o resultado de relações de pura dominação que causam constrangimento ou repressão da liberdade do indivíduo. O governo de si é produzido pela estimulação da autoconsciência, maximizando e correlacionando as capacidades intelectuais e emocionais, fundamentais para a produção de indivíduos que estejam livres para escolher. O sujeito deve ser educado e persuadido (seduzido) a encontrar uma espécie de aliança entre objetivos e ambições de ordem pessoal e atividades valorizadas social e institucionalmente. Os sujeitos moldam suas vidas através das escolhas que fazem na família, no trabalho, no lazer etc. Muitas vezes, o Estado e as instituições agem à distância sobre essas escolhas, forjando uma simetria entre as tentativas dos indivíduos de atribuir sentido à sua própria vida, de

Educação \& Realidade, Porto Alegre, v. 39, n. 2, p. 391-412, abr./jun. 2014 407

Disponível em: <http://www.ufrgs.br/edu_realidade> 
O Discurso da Qualidade da Educação e o Governo da Conduta Docente

obter sucesso, reconhecimento, segurança, visibilidade e os valores políticos de eficiência, produtividade e ordem social. Somos capacitados por meio de linguagens, critérios e técnicas, como o automonitoramento e a confissão, para agir sobre nossos corpos e almas, pensamentos e condutas a fim de obtermos felicidade, sabedoria, riqueza e realização (Rose, 1998).

Pode-se perceber que, divididas entre posições que oscilam entre a crítica ao IDEB, como um indicador de qualidade do ensino e da aprendizagem na Educação Básica, e a crença na sua necessidade, como política que está atrelada a outras demandas da escola e do trabalho docente (como mais recursos financeiros nas escolas, melhorias nas remunerações e carreiras, mais qualificação etc.), essa política termina por capturar as professoras entrevistadas, comprometendo-as e (auto) responsabilizandos-as com os processos e resultados dessas avaliações.

Governar através das escolhas reguladas de sujeitos responsáveis e autônomos constitui-se num tipo de governo e autogoverno das condutas das professoras entrevistadas independentemente das suas condições de trabalho, por mais precárias que fossem, pois acreditavam que as dificuldades seriam vencidas pelo seu comprometimento e dedicação pastoral. Assim, como ensinam alguns dos autores da vertente que centralmente inspira este artigo, a regulação do comportamento dos sujeitos necessita do desejo de cada indivíduo de governar livremente sua própria conduta a serviço da maximização de uma versão de felicidade e realização que considere como sua (Rose, 1998).

\section{Considerações Finais}

O discurso da responsabilização dos sujeitos e escolas pelo alcance do padrão de qualidade expresso na elevação do IDEB marcou os discursos das professoras pesquisadas, produzindo não apenas o tipo de governo exercido sobre as políticas educacionais, como também e, ao mesmo tempo, regimes éticos que visavam o autogoverno dos sujeitos, o governo de si, de suas práticas, condutas e identidades.

As professoras atribuíram legitimidade às políticas de avaliação e assumiram a responsabilidade pelos resultados alcançados com o IDEB. As tecnologias de regulação e controle foram adotadas na gestão do trabalho escolar e nos desempenhos docentes, almejando-se a maximização dos resultados, o que gerou euforia e esperança, aliadas à desconfiança, vergonha, culpa e dor.

Ao julgarem suas ações docentes, em relação aos padrões do IDEB, as professoras julgaram-se a si mesmas, como profissionais que deveriam assumir a culpa pelos baixos resultados e a responsabilidade pelos avanços nos índices, constituindo regimes de verdade e relações de poder-saber nas quais a profissional e a pessoa da professora, unidas num único sujeito capturado pelo próprio discurso, deveria fazer algo consigo mesma, promovendo certas ações dirigidas ao alcance da

408 Educação \& Realidade, Porto Alegre, v. 39, n. 2, p. 391-412, abr./jun. 2014 Disponível em: <http://www.ufrgs.br/edu_realidade> 
norma e do padrão de qualidade legitimado. Assim, como expressaram as professoras, o discurso melhorar o índice de aprovação com garantia de aprendizagem, deveria orientar o trabalho pedagógico na busca da qualidade do ensino mensurada pelo IDEB.

O discurso oficial tratou de fabricar o indivíduo ativamente responsável e passou a integrar os sujeitos pesquisados num regime ético de identificações e obediências que colocavam em evidência escolhas profissionais e pessoais. O governo de si e dos outros visava, em última instância, favorecer o delineamento de identidades docentes marcadas por um profissionalismo performativo.

No contexto pesquisado, o discurso oficial da qualidade da educação foi legitimado pelos sujeitos, articulado com outras demandas que alinharam a preocupação com a evolução do IDEB ao reconhecimento da necessidade de melhorar a aprendizagem, as condições de trabalho, a remuneração e a valorização profissional, produzindo um consenso híbrido. Criou-se, assim, a ideia de qualidade via IDEB como um regime de verdade capaz de articular as demandas dos diferentes sujeitos que passaram a agir em torno desse discurso hegemônico, contingente e precário. Em nome desse acordo, e criando expectativas, as professoras jogaram-se na luta por melhorar seus desempenhos, acreditando estarem cumprindo seu papel enquanto profissionais competentes e comprometidas com a causa instituída: a melhoria da qualidade da educação.

Assim, as políticas voltadas à melhoria da qualidade da educação, pela via da maximização dos índices de avaliação das escolas e redes públicas de ensino, engendraram tecnologias de governo e autogoverno que intensificaram a vigilância sobre o trabalho pedagógico e, ao mesmo tempo, causaram impactos nas condutas docentes, forjando a fabricação de identidades performativas de autorresponsabilização pelo êxito nos resultados. Com isso, as contingências sociais e culturais, que circunstanciavam o cotidiano das escolas e o trabalho docente, foram negligenciadas.

Recebido em 31 de julho de 2013 Aprovado em 03 de março de 2014

\section{Notas}

1 O IDEB é o resultado do cálculo de uma média numérica que cruza as taxas de repetência e evasão escolar com os desempenhos apresentados pelos/as alunos/as nas avaliações nacionais do Ensino Fundamental.

2 Este artigo foi produzido a partir da Tese de Doutorado intitulada: "Os movimentos de recontextualização da política compromisso todos pela educação na gestão do Plano de Ações Articuladas (PAR) e seus efeitos: um estudo de caso no município de Pinheiro Machado (RS)", na qual o discurso de autorresponsabilização para a melhoria da qualidade da educação via elevação do IDEB é analisado como um dos efeitos das políticas nacionais de avaliação que atua no governo da conduta docente (Voss, 2012).

Educação \& Realidade, Porto Alegre, v. 39, n. 2, p. 391-412, abr./jun. 2014.

Disponível em: <http://www.ufrgs.br/edu_realidade> 
3 Nas investigações de Foucault (1984; 1985; 1987; 1988; 1993) são problematizadas diferentes tecnologias de poder, como a tecnologia do poder disciplinar, a biopolítica, as tecnologias do eu, a tecnologia confessional, etc., sendo estas definidas enquanto mecanismos através dos quais o poder se articula com o corpo, seja nas prisões, no hospício, nas escolas ou, ainda, no campo da psiquiatria, da sexualidade etc. Com o termo tecnologias, nesta situação específica, quer-se significar os modos pelos quais as políticas educacionais em questão operam sobre os gestores e os docentes através de um misto de saberes, discursos e práticas (ações, procedimentos etc.), de modo a obter um campo de possibilidades ou de respostas desses sujeitos (de suas ações, de suas sensibilidades e pensamentos) que atendam a objetivos e finalidades estabelecidas anteriormente de modo administrativo (Foucault, 1979; Rose, 1998; 2002).

4 De acordo com o estatuto social do TPE, esta organização não tem fins econômicos ou lucrativos e foi criada com o objetivo de fomentar o capital social da nação e contribuir para assegurar o direito à Educação Básica de qualidade para todos. Entre seus objetivos estratégicos estão cinco metas que abrangem especialmente a Educação Básica pública: (1) toda criança e jovem de 4 a 17 anos na escola; (2) toda criança plenamente alfabetizada até os oito anos; (3) todo aluno com aprendizado adequado à sua série; (4) todo jovem com ensino médio concluído até os 19 anos e (5) investimento em educação ampliado e bem gerido. As metas acentuam, também, que os processos de gestão pública devem ser transparentes e, para tanto, há que se divulgar o monitoramento da educação no Brasil, abrangendo estados e municípios, de forma a tornar acessíveis à opinião pública os referenciais educacionais (Voss, 2011, p. 51).

5 Os sujeitos precisam reconhecer seus próprios interesses nessa totalidade discursiva, atribuindo legitimidade ao discurso que, no seu interior, articula o conjunto de múltiplas demandas. Porém, ao constituir-se pela articulação de diferentes, contraditórias e ambivalentes demandas, o discurso representa uma totalidade precária e contingente, passível de perder a qualquer tempo sua legitimidade (Laclau, 2005).

6 No Brasil, o IDEB dos Anos Iniciais do Ensino Fundamental progrediu de 4,2 (em 2007) para 5,0 (em 2011). Já o IDEB nacional dos Anos Finais passou de 3,8 (em 2007) para 4,1 (em 2011). A defasagem do IDEB nos Anos Finais também ocorre nos índices alcançados pelo Rio Grande do Sul (3,7 em 2007 e 3,9 em 2011), sendo ainda maior no município pesquisado (2,7 em 2007 e 3,8 em 2011). Pesquisado em: <http://ideb.inep.gov.br/resultado>. Acesso em: 21 mar. 2013.

\section{Referências}

BALL, Stephen. Reformar Escolas/Reformar Professores e os Terrores da Performatividade. Revista Portuguesa de Educação, Braga, Portugal, Universidade do Minho, v. 15, n. 02, p. 3-23, 2002.

BALL, Stephen J. Profissionalismo, Gerencialismo e Performatividade. Cadernos de Pesquisa, São Paulo, Fundação Carlos Chagas v. 35, n. 126, p. 539-564, set./dez. 2005.

BALL, Stephen J. Performatividades e Fabricações na Economia Educacional: rumo a uma sociedade performativa. Educação e Realidade, Porto Alegre, v. 35, n. 2, p. 37-55, ago./set. 2010 .

BRASIL. Decreto Presidencial n. 6.094, de 24 de abril de 2007. Dispõe sobre a implementação do Plano de Metas Compromisso Todos pela Educação, pela 
União, em regime de colaboração com Municípios, Distrito Federal e Estados. Diário Oficial da União, Poder Executivo, Brasília, DF, 24 de abr. 2007.

BRASIL. Conselho Nacional de Educação. Parecer CNE/CP 009/2001, de 08 de maio de 2001. Diretrizes Curriculares Nacionais para a Formação de Professores da Educação Básica, em nível superior, curso de licenciatura, de graduação plena. Diário Oficial da União, Brasília, DF, 18 de jan. 2002, seção 1, pag. 31.

FOUCAULT, Michel. A Governamentalidade. In: FOUCAULT, Michel. Microfísica do Poder. 9. ed. Rio de Janeiro: Graal, 1979. P. 277-293.

FOUCAULT, Michel. História da Sexualidade II. O uso dos prazeres. Rio de Janeiro: Graal, 1984.

FOUCAULT, Michel. História da Sexualidade III. O cuidado de si. Rio de Janeiro: Graal, 1985.

FOUCAULT, Michel. Vigiar e Punir. 5. ed. Rio de Janeiro: Vozes, 1987.

FOUCAULT, Michel. História da Sexualidade I. A vontade de saber. Rio de Janeiro: Graal, 1988.

FOUCAULT, Michel. História da Loucura na Idade Clássica. 3. ed. São Paulo: Perspectiva, 1993.

FOUCAULT, Michel. A Arqueologia do Saber. 7. ed. Rio de Janeiro: Forense Universitária, 2008a.

FOUCAULT, Michel. Nascimento da Biopolítica: curso dado no Collège de France (1978-1979). São Paulo: Martins Fontes, 2008b.

FREITAS, Luiz Carlos de. Os Reformadores Empresariais da Educação: da desmoralização do magistério à destruição do sistema público de educação. Educação \& Sociedade, Campinas, v. 33, n. 119, p. 379-404, abr./jun. 2012.

GARCIA, Maria Manuela A. Didática e Trabalho Ético na Formação Docente. Cadernos de Pesquisa, São Paulo, v. 39, n. 136, p. 225-242, jan./abr. 2009.

GATTI, Bernadete A. Avaliação de Sistemas Educacionais no Brasil. Revista de Ciências da Educação, São Paulo, n. 9, p. 7-18, 2009.

LACLAU, Ernesto. La Razón Populista. Buenos Aires: FCE, 2005.

LARROSA, Jorge A. Tecnologias do Eu e Educação. Petrópolis: Vozes, 1994.

MAUÉS, Olgaíses C. Reformas Internacionais da Educação e Formação de Professores. Cadernos de Pesquisa, São Paulo, n. 118, p. 89-117, mar. 2003.

OLIVEIRA, Dalila A. A Reestruturação do Trabalho Docente: precarização e flexibilização. Educação \& Sociedade, Campinas, v. 25, n. 89, p. 1127-1144, set./ dez. 2004.

PETERS, Michael; MARSHALL, James; FITZSIMONS, Patrick. Gerencialismo e Política Educacional em um Contexto Global: Foucault, neoliberalismo e a doutrina da auto-administração. In: BURBULES, Nicholas C.; TORRES, Carlos Alberto (Org.). Globalização e Educação: perspectivas críticas. Porto Alegre: Artmed, 2004. P. 76-89.

ROSE, Nikolas. Governando a Alma: a formação do eu privado. In: SILVA, Tomaz Tadeu da. Liberdade Reguladas: a pedagogia construtivista e outras formas de governo do eu. Petrópolis: Vozes, 1998. P. 30-45.

ROSE, Nikolas. Inventando Nossos Eus. In: SILVA, Tomaz Tadeu da (Org.). Nunca Fomos Humanos: nos rastros dos sujeitos. Belo Horizonte: Autêntica, 2002. P. 139-201.

VOSS, Dulce Mari da S. O Plano de Desenvolvimento da Educação (PDE): contextos e discursos. In: GARCIA, Maria Manuela A.; TURA, Maria de Lourdes R. 
(Org.). Cadernos de Educação, Pelotas, Faculdade de Educação, Universidade Federal de Pelotas, Ano 20, n. 38, p. 43-68, jan./abr. 2011.

VOSS, Dulce Mari da S. Os Movimentos de Recontextualização da Política Compromisso todos pela Educação na Gestão do Plano de Ações Articuladas (PAR) e seus Efeitos: um estudo de caso no município de Pinheiro Machado (RS). 2012. 161 f. Tese (Doutorado em Educação) - Programa de Pós-Graduação em Educação (PPGE), Universidade Federal de Pelotas (UFPel), Pelotas, 2012.

WERLE, Flávia Obino C. Políticas de Avaliação em Larga Escala na Educação Básica: do controle de resultados à intervenção nos processos de operacionalização do ensino. Ensaio, Rio de Janeiro, v. 19, n. 73, p. 769-792, out./dez. 2011.

WHITTY, Geoff. Creating Quase Markets in Education: a review of recent research on parental choice and school autonomy in three countries. Review of Research in Education, v. 22, n. 1, p. 3-47, 1997.

Dulce Mari Silva Voss é doutora em Educação. Integrante do Grupo de Pesquisa Estudos em Educação, Histórias e Narrativas e na Linha de Pesquisa Políticas Educacionais e Reformas na Educação Básica, cadastrada no CNPQ. Professora Adjunta da Universidade Federal do Pampa, Campus Bagé, atuante na área da Educação nos Cursos de Licenciaturas. E-mail: dulcevoss@gmail.com

Maria Manuela Alves Garcia é doutora em Educação e Professora Associada da Universidade Federal de Pelotas, atuando no Programa de Pós-Graduação em Educação dessa Instituição na Linha de Pesquisa Currículo, Profissionalização e Trabalho Docente. Desenvolve pesquisas e estudos que relacionam os temas das políticas curriculares e das reformas educacionais e seus efeitos no campo da formação de professores e do trabalho docente. E-mail: garciamariamanuela@gmail.com 